\title{
IMPORTÂNCIA DA LICENCIATURA EM ENFERMAGEM NA COMPREENSÃO DE ENFERMEIROS
}

\author{
Eduardo Neves da Cruz de Souza ${ }^{\text {ID } 1}$ e Elis Maria Teixeira Palma Priotto (D)2
}

\section{Resumo}

Enfermeiro licenciado é um profissional que atua na saúde, nos vários níveis de atenção, na educação básica e na docência em educação profissional, ambas as funções se integram e contribuem com a pratica profissional generalista em enfermagem no saber da educação. Objetivou-se, aqui, analisar a opinião dos egressos do curso de Enfermagem quanto à contribuição da licenciatura na formação do enfermeiro e no exercício profissional, evidenciando sua relevância, limitações e acerca de seu oferecimento concomitante ao bacharelado. O método utilizado baseou-se em um estudo exploratório, descritivo, de abordagem qualitativa. Utilizouse questionário online semiestruturado. Constatou-se que dos 27 egressos entrevistados, a titulação Enfermeiro licenciado é representativa e contribui ao exercício profissional, sendo que, mesmo em unidades exclusivamente assistenciais, existe a necessidade de o enfermeiro exercer as habilidades de ensino, uma vez que é papel deste profissional promover educação em saúde para toda a equipe de enfermagem e para a sociedade em geral. Confirmando que a oferta concomitante da Licenciatura com o Bacharelado auxilia no exercício profissional, e no desempenho das ações educativas, tanto na área assistencial, como na docência. As discussões realizadas possibilitam reflexões quanto à importância da licenciatura na formação do enfermeiro e na reestruturação das diretrizes da enfermagem para a formação do enfermeiro docente.

Palavras-chave: Licenciatura em Enfermagem; Docente; Exercício profissional.

\section{IMPORTANCE OF NURSING LICENSING IN NURSING UNDERSTANDING}

\section{Abstract}

Licensed nurse is a professional who works in health, in the various levels of care, in basic education and in teaching in professional education, both integrate and contribute to the general professional practice in nursing in the knowledge of education. It aimed to analyze the opinion of the graduates of the Nursing course regarding the contribution of the degree in the training of nurses and in professional practice, evidencing its relevance, limitations and regarding its concurrent offer to the bachelor's degree. The method used based on an exploratory, descriptive study, with a qualitative approach. Semi-structured online questionnaire was used. It was found that of the 27 graduates interviewed, the degree of licensed nurse is

${ }^{1}$ Especialista em Auditoria de serviços de saúde. Bacharel e Licenciado em Enfermagem pela Universidade Estadual do Oeste do Paraná (UNIOESTE). Docente colaborador do curso de Bacharelado e Licenciatura em Enfermagem da UNIOESTE, Campus de Foz do Iguaçu-Paraná.

${ }^{2}$ Doutora em Ciências/Saúde Pública pela Universidade de São Paulo (USP). Professora Adjunta do curso de Bacharelado e Licenciatura em Enfermagem e Pós-Graduação da UNIOESTE, Campus de Foz do Iguaçu- Paraná. Líder do grupo de pesquisa em Ensino, pesquisa e prevenção da violência e vulnerabilidades sociais GEPENSE/UNIOESTE/CNPq.

(c) (1)(3) Perspectivas em Diálogo, Naviraí, v. 8, n. 16, p. 218-234, jan./abr. 2021. 
representative and contributes to professional practice, and even in exclusively care units there is a need for nurses to exercise teaching skills, since it is the role of this professional to promote health education for the entire nursing team and for society in general. Confirming that the concurrent offer of the Licenciatura with the Bacharelado helps in the professional exercise, and in the performance of the educational actions in the assistencial area as in the teaching. Enabling reflections on the importance of the degree in the training of nurses and in the restructuring of nursing guidelines for the training of teaching nurses.

Keywords: Nursing Degree; Teacher; Professional practice.

\section{Introdução}

O profissional enfermeiro é formado em um curso de bacharelado, mas como os cursos de bacharelado não estão focados na capacitação de professores, a formação pedagógica passa a ser uma alternativa para complementar os estudos e ficar apto a seguir a carreira docente, no entanto, essa formação pedagógica tem, geralmente, um ano ou um ano e meio. Enquanto a graduação em enfermagem (de quatro a cinco anos) com licenciatura forma o enfermeiro docente, tendo suas vantagens por habilitar no desenvolvimento de competências para atuar no cenário da formação técnica profissional com regências de aulas teóricas e práticas, elaboração de projetos e programas de saúde em escolas de educação básica e em cursos técnicos profissionalizantes em saúde.

Essa formação teve seu início com a Lei de Diretrizes e Bases da Educação Nacional (LDB) e a Reforma Universitária de 1961 e 1968, e obteve seu destaque na década de 1980, com a elaboração das novas propostas curriculares para o curso de graduação em Enfermagem (BEZERRA; et al, 2012).

Os Cursos de Licenciatura em Enfermagem foram reconhecidos pelo Parecer no 837, aprovado em 1968 (Proc.995/68-CFE). O documento estabelecia que a formação pedagógica em Enfermagem fosse realizada no mesmo ou em outro estabelecimento, desde que legalmente reconhecido para tanto, e poderia também se desenvolver paralelamente ao curso de graduação mediante acréscimo das horas aulas correspondentes, bem como o licenciado em Enfermagem obteria registro definitivo para o ensino, na escola de segundo grau (atualmente Ensino Médio), das disciplinas e práticas educativas relacionadas com essa especialidade.

Destaca-se que a licenciatura em Enfermagem prepara o enfermeiro com conhecimentos e habilidades direcionadas à formação de técnicos e auxiliares de Enfermagem, assim como à direção e coordenação das instituições de ensino que oferecem tais cursos. Para tanto, a Portaria Ministerial no 13/69 - MEC, publicada no Diário Oficial da União em 23 de janeiro do mesmo ano, na qual se instituiu a Licenciatura em Enfermagem para a formação pedagógica do enfermeiro, cita o direito ao registro definitivo como professor das disciplinas e atividades relacionadas à Enfermagem, produzindo e difundindo conhecimento na área do ensino médio e profissionalizante (técnico e auxiliar de Enfermagem, entre outros da saúde) com elaboração, implementação e avaliação de projetos e ações de coordenação no processo de ensino-aprendizagem em cursos de Enfermagem.

Cabe ressaltar que foi na década de 1990 que se buscou a superação do modelo tecnicista de ensino, adequando-se às características do modelo de saúde centrado 
no indivíduo, família e comunidade, de acordo com os pressupostos do Sistema Único de Saúde (SUS), modificando-se significativamente o perfil de professores e alunos das escolas de enfermagem (BONFIM; TORRES, 2002).

Todavia, o fortalecimento da licenciatura em Enfermagem se fez com a promulgação da LDB de 1996, passando a vigorar que, toda a formação de docentes, desde a educação infantil até o ensino médio, deve ocorrer em nível superior, em cursos de graduação plena, em Universidades e Institutos Superiores de Educação (BRASIL, 1996). A LDB, em 2001, estabeleceu, ainda, as Diretrizes Curriculares Nacionais dos Cursos de Graduação em Enfermagem (BRASIL, 2001), lançando um duplo desafio na formação de enfermeiros: o fortalecimento da discussão acerca das dimensões pedagógicas contempladas no curso de Bacharelado e a reestruturação da Licenciatura (SANTOS, et al, 2014).

Mais especificamente em relação a Enfermeiro licenciado, esta foi incluída no Parecer n.o 163/71, do Conselho Federal de Educação, que determinou o novo currículo do curso de Enfermagem, como uma das diversificações a serem seguidas pelo estudante que conclui o Curso de Graduação de Enfermagem. Estas eram anteriormente feitas para as áreas de Enfermagem Obstétrica e de Enfermagem de Saúde Pública e, com este Parecer, foi incluído a área de Enfermagem MédicoCirúrgica e a área de Ensino (Licenciatura).

No Brasil, não tem muitos cursos de licenciatura em Enfermagem, os autores Correa e Sordi (2018) comentam que, em 2015, no cadastro Nacional de cursos e Instituições de Educação Superior na Plataforma e-MEC,29 nos sites e por contatos telefônicos com universidades, encontraram 24 cursos ativos, sendo 18 ofertados por universidades públicas e seis por instituições de ensino superior privadas. Esses cursos estão distribuídos em todas as Regiões do país.

Em Foz do Iguaçu (PR- Brasil), mais especificamente o Curso de Enfermagem da Universidade Estadual do Oeste do Paraná (Unioeste) oferece a Licenciatura concomitante ao Bacharelado desde 2003, cuja autorização de funcionamento foi expedida pelo Decreto no. 3637, de 20/09/2004. Neste mesmo ano ocorreu a elaboração e aprovação do Projeto Político Pedagógico (PPP) do Curso, que foi reconhecido inicialmente em 2007. Em 2012, houve nova alteração do PPP, para os ingressantes a partir de 2013, o curso passou a ser oferecido em cinco anos (Res.086/2012-CEPE), e as disciplinas relacionadas à formação pedagógica foram alteradas a partir do $3^{\circ}$ ano, com a inclusão de Língua Brasileira de Sinais (Libras). O projeto pedagógico, no contexto desta Instituição Publica (Unioeste/Foz), tem como objetivo a formação de profissionais críticos e reflexivos, capacitados para lidar com a equipe, com o usuário, com o serviço de saúde e com a atuação na educação básica e em cursos profissionalizantes.

Neste cenário, a formação do Enfermeiro docente se desenvolve no transcorrer do Curso de Graduação, buscando garantir a articulação entre os diferentes âmbitos de conhecimento profissional e da formação pedagógica, articulando as dimensões teóricas e práticas durante todo o processo de ensino e aprendizagem da formação do mesmo.

Diante do exposto, a aproximação da prática profissional do estudante de Enfermagem com a Licenciatura ocorre desde o primeiro ano do curso, com disciplinas nas áreas de Educação e Ciências Humanas, tendo a prática profissional no $3^{\circ}$ e $4^{\circ}$ ano, nas disciplinas de estágio supervisionado de Prática de Ensino I e II, respectivamente. Ambas têm suas atividades voltadas para o Ensino em saúde, 
desenvolvidas pelos acadêmicos em escolas de Educação básica com o Ensino Fundamental II (50 ao 90 ano) e Ensino Médio, em escolas com cursos profissionalizantes em saúde e com disciplinas em saúde em outros cursos profissionalizante, bem como, em instituições de saúde em que a prática educativa em saúde é um requisito de atualização e formação.

Entretanto, a discussão em torno da formação de Enfermeiros docentes ou licenciados reacendeu nesta última década, com contribuições do 130 Seminário Nacional de Enfermagem (SENADEN), em 2012, no qual ocorreu uma reunião, organizada pela Comissão de Educação da ABEn Nacional. Nessa, discutiram a retomada e ampliação do debate sobre a formação de Enfermeiros docentes para a Educação Técnica Profissional em Enfermagem no âmbito dos Cursos de Licenciatura (ABEn, 2012).

Resultando, dessa forma, na publicação da Resolução - CNE/CP 02/2015 (BRASIL, 2015), que define as Diretrizes Curriculares Nacionais para a formação inicial em nível superior (cursos de licenciatura, de formação pedagógica para graduados e cursos de segunda licenciatura), revogando as resoluções anteriormente enfocadas na formação de licenciados.

Entendendo, a partir desta nova resolução, que os cursos de formação pedagógica deverão se adequar às diretrizes, incorporando conteúdos relacionados aos fundamentos da educação, formação na área de políticas públicas e gestão da educação, seus fundamentos e metodologias, direitos humanos, diversidades étnicoracial, de gênero, sexual, religiosa, de faixa geracional, Língua Brasileira de Sinais (Libras), educação especial e direitos educacionais de adolescentes e jovens em cumprimento de medidas socioeducativas (BRASIL, 2015).

Desde modo e sob esta perspectiva, pensar sobre a licenciatura e o bacharelado em Enfermagem possibilitou uma reflexão consciente da formação de seus profissionais, estimulando o refazer do processo de ensino e aprendizagem, a fim de atingir o perfil almejado do Enfermeiro docente.

Neste contexto, docentes envolvidos com o Curso de Licenciatura em Enfermagem da UNIOESTE/Foz do Iguaçu constataram o desafio para a adequação com a resolução CNE/CP 02/2015 (BRASIL, 2015), quanto a importância da formação pedagógica para os acadêmicos em Enfermagem. E diante dessas reflexões, observou-se que, ao longo da trajetória da formação inicial nesta instituição, não houve a realização de avaliações referentes à formação pedagógica dos egressos quanto a importância na formação acadêmica do bacharelado articulado e ocorrendo concomitante à formação do licenciado em Enfermagem.

Assim, este estudo se voltou para buscar as opiniões dos egressos do curso de Enfermagem com licenciatura sobre o oferecimento da licenciatura e sua importância para a formação do Enfermeiro. Refletindo e analisando se a formação pedagógica a licenciatura contribui para o desenvolvimento de competências educativas em enfermagem e se essa permanece acontecendo concomitante ao bacharelado.

Em uma análise mais ampla, a estruturação e escolha pela licenciatura nos cursos em geral, para os egressos, não é por ter conhecimento sobre o que é fazer a licenciatura, e sim, muitas vezes, escolher o curso e ascender ao ensino superior público ou privado, com modalidades como bacharelado e licenciatura (concomitante) dentro do mesmo curso. Sendo essas escolhas não muito fáceis em termos de qualidade de ensino, em carga horaria e oportunidade de inserção no mercado de trabalho. 
O egresso entende que, em nosso país, o profissional bacharel, em geral, é mais reconhecido do que o licenciado, no exercício da carreira docente, e essa valorização pode ser explicada na atuação do campo universitário, nos quais o bacharel ocupa o lugar de autoridade científica.

Entende-se, também, que de acordo a opinião dos autores Massi e Villani (2020), os cursos de licenciatura em Universidades Públicas seriam "apêndices" dos cursos de bacharelado, e tarefa "pouco nobre" ou "pouco legítima", portanto, "relegada aos docentes da área de educação, considerados menos providos de capital político e social" (p. 16). Ou seja, a desvalorização acadêmica e social da licenciatura pode colaborar para que essa modalidade obtenha percentuais de evasão maiores do que os de bacharelado. E no curso de Enfermagem da Unioeste, com a modalidade de licenciatura concomitante ao bacharelado, não é diferente.

Tanto que, há docentes no curso de Enfermagem com licenciatura que defendem a permanência e importância desta, entendendo que os ensinamentos da prática pedagógica agregam valores e experiências no desenvolvimento do exercício profissional dos enfermeiros, independente destes estarem, ou não, em práticas de ensino escolares ou em cursos de formação profissional. Por outro lado, há docentes que preferem o oferecimento desvinculado do bacharelado, entendendo que a licenciatura sobrecarrega o estudante e que os conhecimentos em práticas educativas podem ser obtidos em disciplinas oferecidas que trabalhem a educação em saúde no bacharelado, ou seja, dessa forma evidenciando o não conhecimento de uma formação pedagógica e seus conteúdos.

Nesta concepção, a concomitância da formação bacharel/licenciado pode trazer implicações diversas, sejam benefícios ou prejuízos à vida profissional. Assim, buscou-se ouvir a opinião dos egressos do Curso de Enfermagem quanto as questões: o egresso do curso de Enfermagem de uma Universidade Estadual identifica a licenciatura como contributo indispensável ao exercício profissional? O conteúdo da licenciatura integraliza-se para o desenvolvimento de competências educativas em Enfermagem? O oferecimento do bacharelado e licenciatura em enfermagem concomitantemente é a melhor opção.

Entendemos que as respostas a esses questionamentos são importantes, por considerarmos que a proposta pedagógica do curso de Enfermagem com a modalidade em Licenciatura pondera o profissional Enfermeiro Licenciado, um indivíduo ativo no ensino e aprendizado, e suas experiencias podem confirmar a continuação do curso nesta modalidade.

Sob esta perspectiva, o estudo tem como objetivo analisar a opinião dos egressos de um curso de Enfermagem com a modalidade em Licenciatura quanto à contribuição da licenciatura na formação do enfermeiro e no exercício profissional, evidenciando, assim, a sua importância, limitações e acerca de seu oferecimento concomitante do bacharelado.

\section{Metodologia}

Pesquisa básica exploratório-descritivo de abordagem qualitativa, seguindo as etapas preconizadas como: (a) levantamento bibliográfico, (b) questionário online com egressos de Enfermagem que tiveram experiências práticas com o problema pesquisado e (c) análise das respostas quanto à compreensão da interação do bacharelado com a licenciatura (GIL, 2007). 
A opção da escolha desse método se reveste de sentido ao se pensar as experiências vivenciadas por egressos de Enfermagem que cursaram o bacharelado e a licenciatura concomitante, pois constituem um grupo específico. Este se interrelaciona e mostra os significados desta experiência em comum de modo similar, na medida em que estão situados em um mesmo contexto, com experiências semelhantes diante a formação em enfermagem.

Foram incluídos os egressos que concluíram o Curso de bacharelado em Enfermagem com licenciatura, ou seja, os egressos diplomados no período de 2009, 2010, 2011, 2012 e 2013. E foram excluídos os egressos que não responderam o questionário de coleta de dados, no prazo solicitado.

A delimitação do número de participantes foi definida, a priori, de acordo com o número de egressos formados nos cinco anos: 98 profissionais. Sendo delineada a partir das respostas obtidas, totalizando 27 egressos participantes. Destes, seis se formaram em 2009, três em 2010, quatro em 2011, seis em 2012 e oito em 2013. Os participantes foram identificados pela numeração arábica, de 1 a 27.

Os dados foram obtidos entre agosto e setembro de 2015 , por meio de um questionário online, semiestruturado, com questões abertas e fechadas, autoaplicável, através do programa Google Drive, mediante autorização dos participantes e norteados pelas questões. Identificação dos egressos entrevistados e outra de questões direcionadas ao objeto de estudo, como a licenciatura contribuiu para sua formação profissional e/ou para seu trabalho profissional? Quanto ao oferecimento da licenciatura com o bacharelado, em sua opinião, o aluno pode escolher se quer cursar somente o bacharelado, o bacharelado com a licenciatura opcional, o bacharelado com a licenciatura concomitante, justificando sua resposta.

Inicialmente, foi realizado um pré-teste, buscando avaliar o conteúdo, a estrutura e a aplicabilidade em uma população com características semelhantes à população em estudo, com uma amostra de três egressos voluntários, sendo que, posteriormente, esses não fizeram parte da amostra analisada. Na sequência, foram enviadas aos egressos, por meio online, as informações quanto ao objetivo, proposta e o Termo de Consentimento Livre e Esclarecido (TCLE), após a concordância desses, foi enviado o questionário da pesquisa, que responderem e enviaram online aos pesquisadores.

A análise dos dados primários foi realizada por meio da utilização de uma planilha eletrônica e foi norteada pela exatidão e descrição dos fatos e fenômenos da realidade, conforme é preconizado em pesquisas de cunho qualitativo (TRIVINÕS, 1987; GIL, 2007).

Este estudo obteve parecer favorável do Comitê de Ética em Pesquisa em Seres Humanos (CEP) da Universidade Estadual do Oeste do Paraná, registrado sob o parecer de n.0 931.648, conforme preconizado pela Resolução n.0 196/95, que estabelece as Diretrizes e Normas Regulamentadoras de Pesquisas Envolvendo Seres Humanos (BRASIL, 2012).

\section{Resultados e discussões}

Participaram da pesquisa 27 egressos. Desses, 81,48\% são do sexo feminino e $18,51 \%$, do sexo masculino, assim, evidenciando a predominância do sexo feminino na população pesquisada, conforme demonstrando no Quadro I, resultado esse também encontrado em outro estudo com uma diferença significativa entre os 
percentuais, referindo que a faixa etária dos egressos foi de 21 até 23 anos, todas do sexo feminino (SANTOS, et al., 2011). No entanto, quanto a faixa etária neste estudo, foi de 23 a 51 anos.

Quadro I: Perfil dos enfermeiros participaram da pesquisa. Foz do Iguaçu, PR.

\begin{tabular}{|c|c|c|c|c|c|}
\hline Identificação & Gênero & Idade & $\begin{array}{l}\text { Ano de } \\
\text { Formação }\end{array}$ & Especialização & Área de atuação \\
\hline Enfermeiro 1 & $F$ & 29 & 2010 & $\begin{array}{l}\text { Enfermagem do } \\
\text { trabalho }\end{array}$ & Hospitalar \\
\hline Enfermeiro 2 & $\mathrm{~F}$ & 25 & 2013 & Não possui & Atenção Básica \\
\hline Enfermeiro 3 & $M$ & 24 & 2013 & Não possui & Hospitalar \\
\hline Enfermeiro 4 & $\mathrm{~F}$ & 24 & 2013 & Não possui & Hospitalar \\
\hline Enfermeiro 5 & $\mathrm{~F}$ & 25 & 2013 & Saúde da Família & Hospitalar \\
\hline Enfermeiro 6 & $\mathrm{~F}$ & 23 & 2013 & Saúde da Família & $\begin{array}{l}\text { Não trabalha no } \\
\text { momento }\end{array}$ \\
\hline Enfermeiro 7 & $\mathrm{~F}$ & 30 & 2013 & $\begin{array}{l}\text { Gerenciamento em } \\
\text { Saúde }\end{array}$ & $\begin{array}{l}\text { Não trabalha no } \\
\text { momento }\end{array}$ \\
\hline Enfermeiro 8 & $\mathrm{~F}$ & 29 & 2009 & Saúde da Família & $\begin{array}{l}\text { Não trabalha no } \\
\text { momento }\end{array}$ \\
\hline Enfermeiro 9 & $\mathrm{~F}$ & 29 & 2009 & Saúde da Família & Hospitalar \\
\hline Enfermeiro 10 & $F$ & 31 & 2012 & $\begin{array}{l}\text { Gerenciamento em } \\
\text { Saúde }\end{array}$ & Hospitalar \\
\hline Enfermeiro 11 & $\mathrm{~F}$ & 31 & 2009 & $\begin{array}{c}\text { Unidade de Terapia } \\
\text { Intensiva }\end{array}$ & $\begin{array}{l}\text { Não trabalha no } \\
\text { momento }\end{array}$ \\
\hline Enfermeiro 12 & $\mathrm{~F}$ & 51 & 2009 & Saúde da Família & $\begin{array}{l}\text { Não trabalha no } \\
\text { momento }\end{array}$ \\
\hline Enfermeiro 13 & $\mathrm{~F}$ & 25 & 2011 & Educação Permanente & Hospitalar \\
\hline Enfermeiro 14 & $F$ & 25 & 2012 & $\begin{array}{l}\text { Docência do Ensino } \\
\text { Superior }\end{array}$ & Hospitalar \\
\hline Enfermeiro 15 & $\mathrm{~F}$ & 35 & 2012 & Urgência e Emergência & Hospitalar \\
\hline Enfermeiro 16 & $M$ & 33 & 2010 & Fisiologia Humana & Hospitalar \\
\hline Enfermeiro 17 & $\mathrm{~F}$ & 25 & 2013 & Urgência e Emergência & Hospitalar \\
\hline Enfermeiro 18 & $F$ & 26 & 2012 & $\begin{array}{l}\text { Unidade de Terapia } \\
\text { Intensiva }\end{array}$ & Hospitalar \\
\hline Enfermeiro 19 & $\mathrm{~F}$ & 27 & 2011 & Mestrado em Ensino & Hospitalar \\
\hline Enfermeiro 20 & $\mathrm{~F}$ & 26 & 2012 & $\begin{array}{l}\text { Enfermagem do } \\
\text { Trabalho }\end{array}$ & Atenção Básica \\
\hline $\begin{array}{l}\text { mEnfermeiro } \\
21\end{array}$ & $M$ & 30 & 2009 & Não Possui & Atenção Básica \\
\hline Enfermeiro 22 & $M$ & 25 & 2012 & Urgência e Emergência & Atenção Básica \\
\hline Enfermeiro 23 & $\mathrm{~F}$ & 23 & 2013 & Educação em Saúde & Hospitalar \\
\hline Enfermeiro 24 & $\mathrm{~F}$ & 25 & 2011 & $\begin{array}{l}\text { Enfermagem } \\
\text { Obstétrica }\end{array}$ & Hospitalar \\
\hline Enfermeiro 25 & $\mathrm{~F}$ & 36 & 2009 & Gestão Hospitalar & $\begin{array}{l}\text { Não atua no } \\
\text { momento }\end{array}$ \\
\hline Enfermeiro 26 & $M$ & 43 & 2011 & Urgência e Emergência & Atenção Básica \\
\hline Enfermeiro 27 & $\mathrm{~F}$ & 27 & 2010 & Saúde da Família & Atenção Básica \\
\hline
\end{tabular}

Fonte: Dados dos autores (2020).

Na identificação histórica e, ainda, atualmente, a Enfermagem é considerada por muitos como uma profissão feminina, o que poderia estar prejudicando a entrada e a aceitação do enfermeiro-homem na profissão, tanto pela maioria feminina que a 
compõe, quanto pela sociedade (VITORINO; HERTEL; SIMÕES, 2012). O mesmo acontece com a presença das mulheres na Educação Básica brasileira, com índice mais elevado em relação a dos homens (JAEGER; JACQUES, 2017).

Segundo estudo de Moreno-Arroyo et al (2016), realizado na Escola Universitária de Enfermagem da Universidade de Barcelona, em 2013, dos alunos de Enfermagem em licenciatura, 61,5\% tinham idade menor que 25 anos, e 80,7\% eram mulheres, sendo que 56,4\% entraram na Licenciatura de Enfermagem por meio do ensino secundário.

Quanto a procura por aperfeiçoamento profissional, paralelo e contribuindo com isso, observa-se o cenário de crise econômica generalizada no Brasil, a busca de empregos disponíveis e a instabilidade dos mesmos tem se agravado e reflete na preparação e formação dos alunos em Enfermagem, buscando ajustar e melhor oportunizar no Ensino Superior (ES) às necessidades do mercado de trabalho (VALENTE; VIANA, 2006), trazendo consigo a adoção das melhores estratégias para obter e manter o trabalho.

Diante disso, o estudo evidenciou que, dos Enfermeiros respondentes, 23 possuem curso de especialização concluído, sendo $14,81 \%$ destes na área da educação e ensino. Os dados obtidos também demonstram que a maior inserção de trabalho destes profissionais foi em hospitais e serviços de assistência de enfermagem. Sendo que apenas seis dos entrevistados atuam na área de ensino em Enfermagem. Cinco atuam na assistencia e no ensino e dezesseis Enfermeiros não exercem atividade em ensino, mas relataram ter interesse em trabalhar na área.

Resultado equivalente à pesquisa de Puschel, Inácio e Pucce (2008), que, após entrevistar 175 enfermeiros formados no ano de 2008, identificou que houve dificuldades para a inserção no mercado de trabalho devido à falta de aperfeiçoamento profissional, relatada por $41,66 \%$ de todo o grupo entrevistado.

Nesta perspectiva, destaca-se a necessidade de formação em ensino, uma vez que o perfil do enfermeiro docente não está inserido somente em conhecimentos técnicos/instrumentais, ou seja, necessita ser focada na formação de um ator social, comprometido com as políticas públicas de saúde e educação, reconhecendo o Sistema Único de Saúde (SUS) para além de um grande empregador, mas como condutor de um serviço social de qualidade (SILVEIRA; CORREIA, 2005). É o que um dos enfermeiros entrevistados comenta:

[...] Em todas as situaçoes profissionais a formação em ensino contribui, pois trabalhamos com equipe, com pessoas, e constantemente estamos realizando educação em serviço que necessita de conhecimentos sobre didática, com uma abordagem mais prática, mais acessível (Enf. 10).

Em relação a atuação dos profissionais entrevistados ser ou não na área da saúde, os dados obtidos revelam que a grande maioria está na área assistencial de enfermagem, 77,77\%, assim, 22,22\% são enfermeiros da Atenção primária de saúde; 33,33\%, do serviço hospitalar; e 7,4\%, são enfermeiros residentes em Enfermagem. Confirmado, dessa forma, por Carvalho et al (2013), que a força de trabalho da Enfermagem se destaca no Setor Público, com quase um milhão de trabalhadores exercendo atividades de Enfermagem, seja na assistência ambulatorial, nas Unidades básicas de saúde e centros de saúde, unidades de múltiplas especialidades, entre elas, os hospitais. Na sequência, o enfermeiro 
entrevistado comenta sobre a sua contratação, que não teve ênfase a licenciatura, porém:

[...] A licenciatura não teve relevância no processo de contratação, porém, me auxilia diariamente na execução do meu trabalho, mostrando que o enfermeiro pode estar em todas as áreas assistenciais, que agregando ao conhecimento didático e pedagógico pode contribuir (Enf. 5).

Quanto a inserção no primeiro emprego dos Enfermeiros egressos entrevistados, $77,77 \%$ foi por meio de processo seletivo, ou seja, as oportunidades se evidenciam na rede pública, o estatutário e o celetista, na rede privada (RIZZOTO, 2013). Sabe-se que no mercado de trabalho, atualmente, constata-se que os egressos enfermeiros, em sua maioria, são constituídos de jovens. Tendo no setor público o maior número de possibilidades para iniciar, sendo a rede estadual a que mais tem profissionais e, na sequência, os municípios. Os entrevistados não referiram dificuldades para a conquista do primeiro emprego.

Mais especificamente, quanto a análise na formação da licenciatura de enfermagem na Unioeste Foz do Iguaçu, os dados mostraram que 70,37\% dos enfermeiros afirmaram terem sido favorecidos para conseguir seu primeiro trabalho por ter cursado a licenciatura, e que os mesmos referem que a formação em educação/ensino teve relevância para as atividades no primeiro emprego. Como pode ser percebido nas falas abaixo:

[...] As aulas tiveram uma grande contribuição no modo como eu oriento a minha equipe. Eu acredito que as aulas de licenciatura e principalmente o estágio docente, me ensinaram a como ensinar e orientar de um modo mais didático, e eu utilizo muito isso no meu trabalho (Enf. 2).

[...] Com toda certeza. A licenciatura me tornou mais segura em relação a comunicação com a equipe, me capacitou a explicar e utilizar métodos didáticos de integração da equipe, e pacientes (Enf. 7).

Sabe-se que a formação pedagógica do enfermeiro teve seu ápice em 1980, e que, em 1990, a formação em nível superior e médio se estruturou para sair do modelo tecnicista e buscar a qualificação dos trabalhadores da enfermagem, aprimorando a formação pedagógica dos licenciados com vistas às DCNs (2001), a qual enfatizou a necessidade de qualificação profissional na formação do bacharel de Enfermagem ao processo de ensino-aprendizagem.

Neste campo, pode-se refletir sobre a objetividade da licenciatura em enfermagem, que busca habilitar profissionais da saúde em educação, para que estes sejam trabalhadores responsáveis, cooperativos, inovadores, com habilidades e competências de ensino cabíveis para a rotina de trabalho em quaisquer unidades de saúde (MELO; et al, 2017).

No entanto, os bacharéis enfermeiros, ao exercer a docência do ensino profissionalizante em enfermagem, esbarram no conhecimento da didática e da pedagogia, pois, durante o bacharelado, a educação ainda atenta para as atividades assistenciais de caráter curativo e fragmentado, preparando o aluno para o cuidado das tarefas diretas ao paciente (VALENTE; VIANA, 2006).

Logo, o exercício da docência irá exigir não só um amplo lastro de saberes diversificados, mas uma aprendizagem contínua, tida como fundamental na carreira profissional, alicerçada pelo aporte de saberes do professor, como arranjo de uma 
arte específica que identifica um ofício mediado pela teoria e pela prática, que vem a ser a compreensão do saber ensinar do professor de profissão (CAVALCANTI, 2015).

Sendo assim, compreender e conjeturar sobre a existência da Licenciatura no curso de Enfermagem possibilita ver a formação e a ação pedagógica do profissional como algo a ser recuperado com seu devido significado. Pois, entendendo que é no processo de ensino-aprendizagem, o enfermeiro docente precisa ter noção do significado social de sua profissão, que segundo Basso (1998), ser professor consiste em ensinar, atrelando esse significado a um sentido pessoal atribuindo a sua atividade docente (ASBAHR, 2005). Por essa razão, a atividade pedagógica do enfermeiro deve estar associada a metas e objetivos definidos e a uma sistematização e intencionalidade ao ensinar os conteúdos curriculares em saúde.

Quanto à licenciatura concomitante à graduação de Enfermagem, os dados obtidos mostram que $59,25 \%$ dos enfermeiros entrevistados afirmaram que a licenciatura deve se manter vinculada a graduação de Enfermagem. Evidenciando que o conteúdo da licenciatura se integraliza para o desenvolvimento de competências educativas em Enfermagem, e o egresso do curso de Enfermagem da Unioeste identifica a licenciatura como contributo indispensável ao exercício profissional. Ou seja, a licenciatura contribuiu em sua formação profissional.

Os relatos apontam de forma positiva que, independentemente do âmbito de trabalho do enfermeiro, seja este assistencial, administrativo e/ou ensino, existe a necessidade eminente deste profissional estudar e se aperfeiçoar para desempenhar atividades pedagógicas de educação em saúde. Assim, é possível desenvolver práticas educativas e promover treinamentos aos profissionais que compõem a sua equipe, uma vez que é papel deste profissional. Conforme se observa nas narrativas abaixo:

[...] Trabalhei muito com a parte de educação, assim as disciplinas de licenciatura me deram embasamento para montar as oficinas, aulas, palestras (Enf. 18).

[...] Diretamente eu não usei o conteúdo das aulas no meu trabalho (hospitalar), mas as aulas de licenciatura tiveram uma grande contribuição no modo como eu oriento a minha equipe. Eu acredito que as aulas de licenciatura e principalmente o estágio docente que, me ensinaram a como ensinar e orientar de um modo mais didático, e eu utilizo muito isso no meu trabalho (Enf. 10).

Outro aspecto referido pelos egressos foi quanto ao trabalho atual do grupo entrevistado, 23 enfermeiros descreveram que o processo de prática educativa é uma habilidade de uso diário no serviço.

[...] Para a prática de educação continuada e treinamentos, é fundamental utilizar os conteúdos aprendidos durante a licenciatura (Enf. 4).

Os egressos ressaltaram, ainda, que o conhecimento adquirido na licenciatura favorece para adequar o processo ensino aprendizagem na relação educador/educando. Ou seja, auxilia para uma comunicação mais efetiva, e no desenvolvimento de atividades de educação para a saúde.

Por outro lado, a história registra que as Diretrizes Curriculares Nacionais de Saúde (DCNS), verificando a necessidade da capacitação pedagógica no bacharelado 
e na procura pela qualidade dos serviços de saúde, incentivou as instituições de saúde públicas e privadas a investirem na qualificação profissional pela via do ensino formal e na educação permanente, com a finalidade da preparação e qualificação dos trabalhadores da área de saúde (BRASIL, 2004; DAVINI, 2009). E define que a licenciatura poderia acontecer em cursos com projetos político-pedagógicos próprios, desvinculados do bacharelado (BRASIL, 2001).

Porém, ao contrário do esperado, a grande maioria dos cursos de graduação em Enfermagem não fornece, em seu currículo, conhecimentos suficientes da didática e pedagogia necessários para o exercício da educação (MAISSIAT e CARRENO, 2010). Revelando-se de grande valor esse compromisso junto à qualificação e formação de profissionais de nível médio que atuarão em distintas instituições de saúde e da ação educativa que exercem junto aos grupos, famílias, indivíduos, equipe de saúde e de Enfermagem (BAGNATO, 2007).

Justificando-se, portanto, a necessidade de o Enfermeiro ter, em sua formação, conhecimentos pedagógicos que o habilitem a atuar como enfermeiro docente, agente de mudanças numa equipe de saúde ou em situações formais de ensino, pois necessita estar preparado para planejar, executar e avaliar ocasiões de ensinoaprendizagem. O ensino da enfermagem vem sendo caracterizado pela constante implementação de mudanças curriculares nos cursos de graduação, e discussões de propostas pedagógicas, compreendendo-se que as diretrizes curriculares para o curso de enfermagem adotam perspectivas mais humanistas (GONÇALVES; et al, 2016).

Os cursos de Licenciatura em Enfermagem, Formação Pedagógica ou Docência para Educação Profissional de Nível Superior e Técnico na área da saúde levam o enfermeiro ao desenvolvimento do seu saber, somando o conhecimento adquirido na graduação ao conhecimento da didática e pedagogia aprendido nesses cursos. Nas competências do docente, esses conhecimentos são fundamentais para que se formem profissionais de nível médio capacitados a atender às necessidades diárias decorrentes de suas funções (VALENTE; VIANA, 2006).

A atividade do enfermeiro licenciado, ou atividade do enfermeiro docente, é uma pratica complexa, mas necessária para a inserção no mercado de trabalho. 0 estudo realizado com os enfermeiros licenciados confirmou que a formação pedagógica favorece a formação do enfermeiro para a docência, com capacidade transformadora.

No questionamento referente a opinião dos egressos na existência do curso de licenciatura na formação dos enfermeiros ser ofertado concomitante com o curso de bacharelado em Enfermagem, 16 egressos relataram que as disciplinas de educação devem se manter atreladas às demais matérias da grade curricular. Como relata três dos entrevistados:

[...] Acredito que todo enfermeiro deveria receber essa forma de curso, devido à importância que temos no processo do cuidado, devemos saber sobre os conceitos clínicos para que possamos ter grande conhecimento sobre as doenças seus processos, mas nada adianta saber o conceito e não saber passar isso para os nossos pacientes. Devido a isso acredito indispensável a licenciatura na formação do enfermeiro (Enf. 12).

[...] Embora tenha uma carga horária extensa, é um diferencial na formação e contribui no perfil do enfermeiro com uma visão e postura diferenciada no mercado de trabalho (Enf. 9).

Perspectivas em Diálogo, Naviraí, v. 8, n. 16, p. 218-234, jan./abr. 2021. 
[...] O enfermeiro trabalha diariamente com atividades educativas, seja na saúde pública ou hospitalar, a licenciatura nos possibilita melhorarmos a observação, a comunicação, a educação permanente que é competência do enfermeiro (Enf. 7).

Enquanto os demais entrevistados relataram que grande parte dos processos de contratação profissional não considera a formação em licenciatura do enfermeiro como diferencial, mas sim, a experiência e prática profissional. Desse modo, acreditam que é oportuno oferecer a licenciatura na modalidade optativa, assim demonstrado em algumas falas:

[...] Nem todos os alunos pretendem lecionar e a licenciatura não tem diferença no mercado de trabalho (Enf. 22).

[...] Nem todos os acadêmicos de enfermagem desejam lecionar um dia, porém são obrigados a cursar essas disciplinas para se formarem. Durante a graduação percebi muitos colegas que não se identificaram com a área, porém tinham que cumprir as disciplinas de licenciatura. Ainda, acredito que a licenciatura não é imprescindível para conseguir um emprego na área hospitalar (Enf. 16).

Entretanto, quando questionados sobre as práticas educativas exercidas no campo de trabalho assistencial, 23 enfermeiros descreveram que o processo educativo é uma habilidade de uso diário no serviço. Nessa perspectiva, destaca-se o papel do processo de ensino e aprendizagem em âmbito hospitalar, no que se refere às pessoas envolvidas na redução dos riscos em saúde, pois a segurança do paciente depende, dentre outros aspectos, da comunicação fundada em confiança mútua, do fluxo de informações de boa qualidade, da aprendizagem organizacional e do compromisso da gestão do conhecimento e da liderança compartilhada (JARDALI, et al, 2011). Ou seja, de qualquer modo, evidencia-se como motivos, chances e possibilidades que o mercado de trabalho oferece para o enfermeiro docente na área da saúde e da educação e, assim, efetivamente comprovar que a licenciatura é mais uma oportunidade no contexto profissional.

Tanto que se observa que a licenciatura é entendida como uma oportunidade de melhor instrumentalizar o egresso para o exercício de seu papel de educador em saúde. Desse modo, segue a fala:

[...] Bom, a licenciatura tornou-se um diferencial em meu currículo. No inicio não achava tão importante, mas a partir do momento que ingressei no mercado de trabalho pude ver como é mais fácil ensinar a sua equipe quando se possui técnicas de ensino. A minha atuação de 2011 a inicio de 2013 foi como docente tanto em Ensino Superior, como em Ensino Profissionalizante, com certeza sem a licenciatura não teria a oportunidade de trabalhar com confiabilidade nessa área. Você aprende a ter visão de professor, de quem aprendeu para ajudar os outros a aprender. Fora que existe a facilidade de escrever trabalhos científicos devido as matérias da licenciatura. O enfermeiro licenciado expande possibilidade de emprego (Enf. 18).

Entre as muitas oportunidades citadas pelos egressos, destaca-se as habilidades técnicas e instrumento de ensino aprendizado apreendidos, como recursos proporcionados pela licenciatura. Como evidenciado no depoimento: 
[...] A licenciatura contribuiu para minha formação profissional, pois o enfermeiro ele é o responsável pelo treinamento da sua equipe, além disso, a licenciatura fornece técnicas de ensino e desenvolve nossas habilidades para que possamos repassar e transmitir novos conhecimentos (Enf. 7).

Evidenciando-se que as opiniões aqui formalizadas afirmam que a formação Enfermeiro docente (com licenciatura), traduzem-se em oportunidades de trabalhos e realizações profissionais.

Neste contexto, as Diretrizes Curriculares de Graduação em Enfermagem corroboram em aspectos que favorecem a formação do enfermeiro-educador (BRASIL, 2001). Cabe destacar as competências e habilidades específicas para essa ação, que indicam que o enfermeiro egresso deve ser capaz de: planejar, participar e implementar programas de formação e qualificação contínua dos trabalhadores de Enfermagem, assim como programas de educação e promoção à saúde, considerando a especificidade dos diferentes grupos sociais e dos distintos processos de vida, saúde, trabalho e adoecimento (SANTOS, et al, 2010).

\section{Considerações finais}

A compreensão da opinião do egresso, atualmente, Enfermeiro docente, sobre sua experiência profissional, permitiu identificar alguns aspectos que se traduzem em possibilidades de reflexões para os que atuam especialmente no âmbito da educação em saúde e do ensino em Enfermagem.

Entendemos que, de acordo com as respostas obtidas nas questões da pesquisa, evidenciou-se que 0 bacharelado em enfermagem com licenciatura concomitantemente deve ser mantido, permitindo, assim, a formação de enfermeiros licenciados.

Compreende-se que as respostas afirmativas obtidas são de extrema importância por reafirmarem e fortalecerem a proposta pedagógica do curso de Enfermagem com Licenciatura e por reverenciarem o respeitável papel que os enfermeiros licenciados, alocados a oportunidades no mercado de trabalho, junto a escolas de formação de profissionais de nível técnico, com contribuições pedagógicas que contemplem em conformidades com as políticas de educação e saúde, um exercício profissional de qualidade.

Este estudo traz contribuições para a enfermagem, na medida que se aporta em uma temática ainda pouco compreendida e paradoxalmente fecunda na trajetória política nacional e do curso para se estruturar e se manter alicerçada para que novos estudos sejam realizados. Ainda que limitado à compreensão e opiniões oriundas de enfermeiros licenciados, remete a ponderações importantes para a estruturação e permanência da formação deste profissional. E sugere-se outros estudos sobre a temática proposta.

\section{REFERÊNCIAS}

ASBAHR, Flávia da Silva. A pesquisa sobre a atividade pedagógica: contribuições da teoria da atividade. Rev. Bras. Educ., Rio de Janeiro, n. 29, p. 108-118, ago. 2005. 
ABEN. Associação Brasileira de Enfermagem. Carta de Belém para a educação em enfermagem brasileira. $13^{\circ}$ Seminário Nacional de Diretrizes para a Educação em Enfermagem. Anais... Belém (PA), Brasil. Associação Brasileira de Enfermagem, 2012. Disponível em:

http://www.abennacional.org.br/images/conteudo/file/CARTA\%20DE\%20BELEM.pd f. Acesso em: 15 maio 2020.

BEZERRA, Ana Lúcia Queiroz; QUEIROZ. Érica dos Santos; WEBER, Juliane; MUNARI, Denise Bouttlet. Processo de educação continuada na visão de enfermeiros de um hospital. Revista Eletrônica de Enfermagem. v. 14, n. 3, p. 618-625, 2012.

BONFIN, Maria Inês do Rego Monteiro; TORREZ, Milta Neide Freire Barron. A formação do formador no PROFAE: refletindo sobre uma proposta na área de enfermagem. In: BRASIL, Ministério da Saúde. Formação de formadores: uma nova docência na educação básica e profissional. Brasília DF, 2002.

BRASIL. Ministério da Educação (BR), Lei No 9.394 em 20 de dezembro de 1996: estabelece as diretrizes e bases da educação nacional. Diário Oficial da União, Brasília (DF) 1996 dez 23; 34 (248) Seção 1:27. p. 833-41.

BRASIL. Ministério da Educação. Conselho Nacional de Educação. Câmara de Educação Superior. Resolução CNE/CES n. 3, de 7 novembro de 2001. Institui as diretrizes curriculares nacionais do curso de graduação em Enfermagem. Diário Oficial da República Federativa do Brasil. Brasília (DF), 9 nov. 2001. Seção 1, p. 37.

BRASIL. Conselho Nacional de Educação (BR). Resolução CNE/CES no 3, de 7 de novembro de 2001: diretrizes Curriculares Nacionais do Curso de Graduação em Enfermagem. Brasília (DF); 2001.

BRASIL. Política Nacional de Educação Permanente em Saúde. Portaria no 198/GM/MS, de 13 de fevereiro de 2004: Brasília (DF), 2004, p. 43-46.

BRASIL. Portaria no 198/GM/MS, de 13 de fevereiro de 2004: institui a Política Nacional de Educação Permanente em Saúde como estratégia do Sistema Único de Saúde para a formação e desenvolvimento de trabalhadores para o setor e dá outras providencias. In: BRASIL, Ministério da Saúde. Política de Educação e Desenvolvimento para o SUS: caminhos para a educação permanente em saúde: polos de educação permanente em saúde. Brasília (DF), 2004, p. 43-46.

BRASIL. Resolução no 466, de 12 de dezembro de 2012. Diretrizes e normas regulamentadoras de pesquisas envolvendo seres humanos. Conselho Nacional de Saúde; 2012.

BRASIL. Resolução No 2, de 10 de julho de 2015 que define as Diretrizes Curriculares Nacionais para a formação inicial em nível superior (cursos de licenciatura, cursos de formação pedagógica para graduados e cursos de segunda licenciatura) e para a formação continuada. 
BRASIL. Ministério da Educação. Cadastro Nacional de Cursos e Instituições de Educação Superior Cadastro e-MEC. In: Regulamentação da Portaria Normativa no 21, de 21/12/2017. (Art. 29), 21/01/2017. Disponível em: https://emec.mec.gov.br/emec/nova. Acesso em: 5 out. 2020.

CARVALHO, Manoela de; SANTOS, Nelson Rodrigues dos; CAMPOS, Gastão Wagner de Souza. A Construção do SUS e o Planejamento da Força de Trabalho no Brasil: breve Trajetória histórica. Saúde em Debate, Rio de Janeiro, v. 37, n. 98, p. 37287 , jul./set. 2013.

CAVALVANTI, Fillipe Manoel dos Santos. A formação em enfermagem no Brasil e as imposições do capital em crise. Dissertação de Mestrado em Educação NPGED - UFS. São Cristóvão, 2015.

CORREA, Adriana Katia; SORDI, Mara Regina Lemes de. Educação Profissional Técnica de nível médio no Sistema Único de Saúde e a Política de Formação de Professores. Texto contexto - enferm. Florianópolis, v. 27, n. 1, e 2100016, 2018. Disponível em:

http://www.scielo.br/scielo.php?script=sci_arttext\&pid=S0104-

07072018000100600\&lng=pt\&nrm=iso Acesso em : 06 jul. 2020.

DAVINI, Maria Cristina. Enfoques, problemas e perspectivas na educação permanente dos recursos humanos de saúde. In: Ministério da Saúde (BR), Secretaria de Gestão do Trabalho e da Educação na Saúde, Departamento de Gestão da Educação em Saúde. Política Nacional de Educação Permanente em Saúde. Brasília (DF); p. 39-56. 2009.

GIL, Antônio Carlos. Como elaborar projetos de pesquisa. 4. ed. São Paulo: Atlas, 2007.

GONÇALVES, Marlene Fagundes Carvalho; ANDRADE, Luciane Sá de; SILVA, Marta Angélica Lossi. (Orgs.). Promoção da saúde na educação básica e a licenciatura em Enfermagem. São Paulo: Iglu, 2016. 275p.

JAEGER, Angelita Alice; JACQUES, Karine. Masculinidades e docência na educação infantil. Rev. Estud. Fem., Florianópolis, v. 25, n. 2, p. 545-570, ago. 2017.

MACHADO, Maria Helena; OLIVEIRA, Eliane; WALDIRLANDO, Lemos; LACERDA, Wagner Ferraz de. Mercado de Trabalho da Enfermagem: Aspectos Gerais.

Revista de Enfermagem em Foco; v. 7, n. esp., p. 35-62, 2016.

MASSI, Luciana; VILLANI, Alberto. O destino social de licenciandos e bacharéis em Química: um estudo de caso sobre a formação de professores no plano

microssociológico. Pro-Posições, Campinas, v. 31, e20170089, p. 1-22, 2020.

Disponível em:

http://www.scielo.br/scielo.php?script=sci_arttext\&pid=S010373072020000100518 $\& \operatorname{lng}=$ en\&nrm =iso. Acesso em: 06 maio 2020. 
MELO, Rosa Cândida de Carvalho Pereira de; QUEIRÓs, Paulo Joaquim; TANAKA, Luiza Hiromi; COSTA, Paulo Jorge; BOGALHO, Catarina Isabel de Deus; OLIVEIRA, Patrícia Isabel da Silva Faria. Dificuldades dos estudantes do curso de licenciatura de enfermagem no ensino clínico: percepção das principais causas. Revista de Enfermagem Referência, v. 4, n. 15 - out./nov./dez. 2017.

MENDONÇA, Constança; HUET, Isabel; ALVES, Mariana Gaio. Da Construção à Validação de um Referencial de Competências para uma Licenciatura em Enfermagem. Revista Portuguesa de Pedagogia, v. 2, n. 1, p. 109-132, jul. 2015. Disponível em:

http://iduc.uc.pt/index.php/rppedagogia/article/view/2324/1522. Acesso em: 08 ago. 2016.

MINAYO, Maria Cecília de Souza. O desafio do conhecimento: pesquisa qualitativa em saúde. Rio de Janeiro: Hucitec, 2004.

MINAYO, Maria Cecília de Souza. Pesquisa Social: teoria, método e criatividade. Petrópolis: Vozes, 1994.

PARANÁ. Decreto Estadual no 2950, de 18/05/2004. Suspensão de a abertura de concurso vestibular para o curso de Graduação em Enfermagem, Campus de Foz do Iguaçu, 2004. Disponível em:

http://www.cee.pr.gov.br/arquivos/File/pdf/Pareceres2009/CES/pa_ces_22_09.pdf. Acesso em: 24 jul. 2020.

PARANÁ. Decreto Estadual no 3637, de 20/09/2004, que ratificou a autorização de funcionamento do respectivo Curso, 2004.

PHILBERT, Larissa Angélica da Silva. Investigação da formação dos estudantes do curso de Licenciatura em Enfermagem para temática sexualidade humana [dissertação]. Ribeirão Preto: Escola de Enfermagem de Ribeirão Preto, Universidade de São Paulo; 2009.

RIZZOTO, Maria Lúcia Frison; GIL, Celia Regina Rodrigues; CARVALHO, Manoela de; FONSECA, Ana Lucia Nascimento; SANTOS, Marieta Fernandes. Força de Trabalho e gestão em saúde: revelações da Avaliação Externa do Programa Nacional de acesso e da qualidade da Atenção Básica do Paraná. Saúde em Debate, Rio de Janeiro, v. 38, n. esp., p. 237-51, out. 2014.

SANTOS, Sueli Maria dos Reis; JESUS Maria Cristina Pinto de; MERIGHI, Aparecida Barbosa; OLIVEIRA, Deise Moura de; SILVA, Marcelo Henrique; CARNEIRO, Carla Toscano. Licenciatura e bacharelado em enfermagem: experiências e expectativas de estudantes. Rev. Gaúcha Enferm., v. 32, n. 4, p. 711-718, 2011.

SANTOS, Lauriana Medeiros Costa Ribeiro; OLIVEIRA, Katia Regina Barros; PADILHA; Jonas Samis Albuquerque de; BORENSTEIN; Maria Itayra Coelho de 
Souza. A licenciatura em enfermagem no Brasil (1968-2001): uma revisão de literatura. Rev. Eletr (Here), v. 5, n. 2, p. 224-238, ago./dez., 2014.

SILVEIRA; Renata; CORRÊA; Adriana Katia. Análise integrativa da literatura (19992003): ensino em educação profissional em enfermagem. Revista de

Enfermagem UERJ, Rio de Janeiro, v. 13, n. 1, p. 91-96, jan.-abr. 2005.

TRIVIÑOS, Augusto Nibaldo Silva. Introdução à pesquisa em Ciências Sociais: a pesquisa qualitativa em Educação. São Paulo: Editora Atlas, 1987.

UNIVERSIDADE ESTADUAL DO OESTE DO PARANÁ. UNIOESTE. Resolução COU/UNIOESTE no 021/97. Aprova Carta-Consulta para implantação de Extensão do Curso de Enfermagem. Disponível em: http://www.unioeste.br/conselhos/resolucoes_COU.asp. Acesso em 24 de nov. 2014.

VALENTE, Campos; VIANA, Lurdes Oliveira de. A formação do enfermeiro para o ensino de nível médio em enfermagem: uma questão de competência. Revista Eletrônica Enfermagem Global, n. 9, nov. 2006. 